\title{
Beyond Co-Existence to Mutual Influence: An Interdisciplinary Method for Psychoanalysis and Religion
}

\section{Amy Bentley Lamborn}

Published online: 11 September 2007

(C) Blanton-Peale Institute 2007

Erratum to: J Relig Health (2007)

DOI 10.1007/s10943-007-9124-3

In this article, the biographical information at the end is incorrect. It should have read as follows: "The author is an Analyst-in-Training at the National Institute for the Psychotherapies."

The online version of the original article can be found under doi:10.1007/s10943-007-9124-3.

\author{
A. B. Lamborn ( $\square)$ \\ Department of Psychiatry \& Religion, Union Theological Seminary (New York City), \\ 5030 Henry Hudson Parkway, Bronx, NY 10471, USA \\ e-mail: al2309@columbia.edu \\ Springer
}

